\title{
Work Role Stressors and Bottom-line Mentality
}

\author{
Justin B. Keeler \\ Ouachita Baptist University \\ 410 Ouachita Street \\ Arkadelphia, AR 71998-0001 \\ Robert L. Webster \\ Ouachita Baptist University \\ 410 Ouachita Street \\ Arkadelphia, AR 71998-0001
}

\begin{abstract}
The purpose of this study was to research how work role stressors are associated with a bottom-line mentality (BLM).Data from 181 professionals from different industries were used in structural equation modeling and multiple regression analysis to determine if work role stressors effect the variable so named "bottom-line mentality". Role ambiguity, role conflict, and role overload were the work role stressors studied to determine their impact, if any, on bottom-line mentalities. This paper describes the data collection process, statistical analyses, and findings, as well as implications for employers and employees and then calls for additional research.
\end{abstract}

Keywords: Work role stressors, bottom-line mentality

\section{Introduction}

Stress is present in every job and all employees experience some form of it. We can attribute it to "losing" our cool, depression, or worse, retaliatory violence at a coworker or manager. In contrast, stress can be a good thing, it can stimulate us to act or persist to achieve a gain. The point is stress can have positive or negative outcomes for a worker, especially in how they may adopt mentalities and mindsets.

The more that we know about outcomes of stress, the better we can understand how specific phenomena occur. The focus of this paper concerns the negative aspects of work role stressors and the possibly of them leading to bottom-line mentalities (BLM). Understanding this relationship may help managers understand how a person "wears" down psychologically at the organization. As a result of wearing down, the employee may be more susceptible to workplace burnout and (or) deviant behavior.

A problem observed many times in a corporate setting is a misunderstanding of how stressor roles take a toll on an employee. There are a host of explanations that may cause stressor role issues ranging from job design, organizational culture, or possibly managerial expectations. While these areas would be fruitful and interesting, they are beyond the scope of this paper. This paper is concerned with understanding how negative role stressors wear on employees and potentially drive them to adopt a specific mentality. The bottom-line mentality may be a phenomenon that this a double edge sword to the employer. On one hand an employee with a BLM is driven to achieve financial gains; however, they may also do it while engaging in social undermining behavior (Greenbaum, Mawritz, \& Eissa, 2012).

The practical relevance of this study is it raises awareness of potential outcomes of role stressors in the workplace that are associated with negative outcomes. At an individual level, job role stressors consume mental resources most likely from coping with the stressors. Because of the coping process along with frustrations of the role stressors, arguably a person becomes vulnerable from mental resource depletion.

Beyond the awareness aspect, this study provides a starting point for managers and organizations to revisit several elements associated with causing role stressors to possibly blunt the outcomes evidenced in this research. Understanding influences that potentially cause or are highly associated with the role stressors can provide a baseline to make adjustments, thus increasing employee work performance and output. 
A practical recommendation is for managers and human resource departments to work together in architecture of job designs. While job design was beyond this research relative to role stressors, it is an important to consider in a practical sense because of relatedness to role stressors. This research demonstrates possible outcomes from role stressors; however, an important managerial component is to address potential concerns that prompt the various role stressors.

\section{Literature Review}

The theory argued to explain the relationships and hypotheses in this paper is based on conservation of resources (COR). This theory suggests individuals try to maintain specific resources and that stress results when there is a loss of the particular resource (Hobfoll, 1989). Hobfoll identified four areas that people try to acquire and maintain: objects (homes, food), personal characteristics (self-esteem, mastery), conditions (social support, finanical security), and energies (time, money, knowledge). A key underpinningof COR is that individuals derive success in coping with stress when they avoid losses of personal characteristics and conditions (p. 516). This being said,work role stressors are comparable to cognitive friction points, resulting in an increase of psychological stress. Based on this premise considering COR, individuals most likely are protecting resources from being lost while also investing resources to thwart the potential losses(Halbesleben, Neveu, Paustian-Underdahl, \& Westman, 2014). As such, utilization of such resources is a response to cope with a combination of role stressors. In this study, the outcome of people to adopt or resort to a mentality of competitiveness laced with something of perceived importance beyond other competing priorities may in fact be a result from the work role stressors having an adverse toll on a worker.

As such, the mentality, known as bottom-line mentality (BLM) may be somewhat of a phenomenon born out of protecting resources because the individual is subjected to the effects of psychological stresses at work. In other words, BLMs may occur as a result of work role stressors and the individual trying to cope with psychological demands that potentially makes them vulnerable to adopting ideas and thoughts of importance that they may otherwise may not support.

\subsection{Employee Bottom-Line Mentality}

Greenbaum et al. (2012) describe this construct as a one-dimensional frame of mind that views colleagues as competition, thus success by coworkers is a threat. Appelbaum and Shapiro (2006) suggest the BLMs may originate from organizational cultural toxicity, thus prompting the adoption and adaption or counter norm behavior. BLM is associated with compromised ethical values and morality because such mentality views these considerations as obstacles in the pursuit of financial success (Sims, 1992). Wolfe (1988) described BLM as an attitude that focuses on determining "worth of instances and events to pay attention to while everything else is discarded" (p.145).

\subsection{Work RolesStressors relationship to Bottom-Line Mentality}

Based on the literature, stress is a concept that has roots in an individual's perception, specifically their assessment of being able to adequately cope with the demands being made upon them or with threats to their wellbeing (Cohen \& Wills, 1985; Karasek Jr, 1979; cf. Lazarus, 1966). Based on a description by Kahn and Byosiere (1992), a stressor is a source of stress, insomuch, they [stressors] are conditions and events that evoke strain. In other words, a stressor can be viewed as an originating event, stimulus, or thing that causes psychological strain, specifically to an individual's cognitive, emotional, and behavioral state of mind. As such, the literature consistently subscribes to and supports three domains of work stressors, specifically conflict, ambiguity, and overload (Bolino \& Turnley, 2005; Coverman, 1989; House, Schuler, \& Levanoni, 1983; Peterson et al., 1995; Rizzo, House, \& Lirtzman, 1970).

Role conflict. Rizzo et al. (1970) describes role conflict as "compatibility-incompatibility in requirements of the role" (p.155). Importantly, role is identified as "a set of expectations about behavior for a position in the social structure" (p.155). Based on these considerations, conflicts are argued to occur within an individual's internal standards, time and resources, behaviors, and organizational expectations when a discrepancy occurs regarding the individual's understanding of their role or function. When demands in these areas exceed what the individual believes is incapable, the role conflict becomes a stressor, especially when confusion exists pertaining to multiple roles (Coverman, 1989). Hall (1972) suggested that attitudes play an important role related to role conflict, in that an individual should accept it [role conflict] as a "fact of life, bear with it and hope it decreases in time" (p.474). 
Importantly, role conflicts impact a person's attitude and frame of mind. This being so, it makes sense that role conflict most likely are correlated to bottom-line mentalities.

Role ambiguity. The description of role ambiguity involves predictability of outcomes, given a behavior, and clarity of behavioral requirement (Rizzo et al., 1970). Importantly, elements exist in an environment for which an individual draws upon to guide their behavior, specifically in "areas of duty, authority, and allocation of time, relationships, directives, policies, and predictability of sanctions as outcomes of behavior (p.156). When an individual is unclear in these areas, role ambiguity surfaces as a stressor because an individual lacks a point of reference in their role, thus finding difficulty in being able to predict and connect to anticipated expectations. This being the case, the individual is strained in understanding interpretable cues in their sensemaking process (Weick, 1995; Weick, Sutcliffe, \& Obstfeld, 2005), thus finding difficulty in coping and responding to demands of possible sources i.e. authority, relationships, etc. This being said, we would expect the relationship to be positively related to BLM.

Role overload. The notion of role overload is described as an employee situation for which the extent of responsibilities demanded exceed what the individual can address and respond, given their available time, abilities, and resources (Rizzo et al., 1970). Bolino and Turnley (2005) expanded on role overload by referring to work by Welbourne, Johnson, and Erez (1998), which argued employees have a job-holder role and organizational-member role. Job-holder refers to "formally described duties and responsibilities the employee must fulfill;" whereas, organizational-member "relates to expectations to be good organizational citizens" (p.741). How does stress play a part in role overload? The individual or employee strives to uphold roles of job-holder and organizational member while trying to address and juggle demands within these domains. Importantly, complementing the demands requires resources that impact self-regulation and attitudes.

\section{Research Questions}

The objectives of this study are to answer the following research questions:

1. Can existing scales be used to produce reliable and valid measurements of role stressors and BLM in the context of this research?

2. What are the mean scores of the role stressors scales and the BLM scale reported by the survey respondents?

3. Do the role stressors, (1) role ambiguity, (2) role conflict and (3) role overload effect BLM?

\section{Methodology}

To examine the relationships between role stressors and employee bottom-line mentality, we recruited 191 working adults using Amazon's Mechanical Turk (mTurk). To qualify to participate in the study mTurk participants had to be currently working and have an mTurk worker credential signifying they had received 95\% positive feedback on prior survey participation. Qualified participants completed the survey containing study variables, received a code verifying completion, and were paid $\$ 0.75$ after we confirmed completion. Ten of the 191 individuals recruited failed the attention check or did not fully complete the survey, thereby reducing the final sample size to 181 for a response rate of $95 \%$. Demographic characteristics of participants completing the survey were 47\% male and 75\%, Caucasian, 12\% Asian American, 4\% Hispanic, 2\% African American, and 7\% other. The average age of respondents was 35.69 years $(\mathrm{SD}=10.88)$, and average tenure at the current organization was 14.02 years $(\mathrm{SD}=9.80)$.

The survey contained previously validated measures for all study variables. Participants responded to measures assessing their role ambiguity, role conflict, role overload, and bottom-line mentality. Respondents also completed a measure for social desirability that was used as a control variable, as is common practice with selfreport data (Spreitzer, 1995).

Role ambiguity. Using Peterson et al.'s (1995) five-item scale, participants rated their own role ambiguity at work. Sample items include "I have clearly planned goals and objectives for my job" and "My responsibilities are clearly defined". Responses to these items were made on a 7-point response scale from $1=$ strongly disagree to 7 $=$ strongly agree $(\alpha=.92)$

Role conflict. Participants provided ratings of role conflict at work using House, Schuler and Levanoni's (1983) eight-item scale. Sample items include "I work with two or more groups who operate quite differently" and "I receive incompatible requests from two or more people". Responses to these items were made on a 7-point response scale from $1=$ strongly disagree to $7=$ strongly agree $(\alpha=.91)$. 
Role overload. Participants assessed their own role overload at work using Bolino and Turnley's (2005) threeitem scale.

Items used are "The amount of work I am expected to do is too great", "I never seem to have enough time to get everything done at work" and "It often seems like I have too much work for one person to do". Responses to these items were made on a 7-point response scale from $1=$ strongly disagree to $7=$ strongly agree $(\alpha=.91)$.

Bottom-line mentality. Using Greenbaum et al.'s (2012) four-item scale, participants rated their own BLM. Sample items include "I only care about business outcomes" and "I treat the bottom line as more important than anything else". Responses to these items were made on a 7-point response scale from $1=$ strongly disagree to $7=$ strongly agree $(\alpha=.92)$.

Control variable. We collected participant responses to a 10-item measure of social desirability (Strahan \& Gerbasi, 1972). Including social desirability as a control variable with self-report data is a common practice used to assess potential response bias (Mitchell \& Ambrose, 2007; Spreitzer, 1995). Sample items include "I'm always willing to admit it when I make a mistake," and "I have never deliberately said something to hurt someone's feelings." Responses to these items were made on a binary response scale of true $=1$ and false $=0$ for questions 1-5; whereas, false $=1$ and true $=0$ for questions 6-10. A social desirability index is computed as the summation of all questions respective of values being one or zero. Considering the control variable, the significant effects reported below remained significant with or without including it.

\section{Results}

To examine the uniqueness of the study variables, we performed confirmatory factor analyses with maximumlikelihood estimation in AMOS 25. Our measurement model involved five factors: role ambiguity, role overload, role conflict, BLM, and social desirability. We randomly combined items for the role conflict measure to create item parcels to reduce the model. This was done in order to maintain a favorable indicator to sample size ratio, as recommended by Bagozzi and Edwards (1998). The results indicated the five-factor model provided a good fit of the data (see Table 1).

Table 1. Results of Confirmatory Factor Analyses

\begin{tabular}{lllllll}
\hline Model & $\chi^{2}$ & $d f$ & ${ }^{\Delta} \chi^{2}$ & ${ }^{\Delta} d f$ & CFI & SRMR \\
\hline 5-factor model & $192.52^{* * *}$ & 95 & & & .96 & .05 \\
4-factor model (1) & $443.78^{* * *}$ & 99 & $251.26^{* * *}$ & 4 & .84 & .08 \\
4-factor model (2) & $652.43^{* * *}$ & 99 & $459.91^{* * *}$ & 4 & .75 & .20 \\
4-factor model (3) & $655.16^{* * *}$ & 99 & $462.64^{* * *}$ & 4 & .75 & .19 \\
3-factor model & $1,045.02^{* * *}$ & 102 & $852.50^{* * *}$ & 7 & .57 & .24 \\
2-factor model & $1,045.87^{* * *}$ & 103 & $853.35^{* * *}$ & 8 & .57 & .24 \\
1-factor model & $1,573.25^{* * *}$ & 104 & $1,380.73^{* * *}$ & 9 & .33 & .25 \\
\hline
\end{tabular}

Note. $\mathrm{CFI}=$ comparative fit index; SRMR = standardized root-mean-square residual.

${ }^{* * *} \mathrm{p}<.001$.

We compared the five-factor model to four alternative models. The first four-factor model had the items of role overload and role conflict loading on the same factor. The second four-factor model had the items of role ambiguity and role conflict loading on the same factor. The third four-factor model had the items of role ambiguity and role overload loading on the same factor. The three-factor model had the items of role ambiguity, role conflict, and role overload loading on the same factor. The two-factor model was the same as the three-factor model except that social desirability was added to BLM. The one-factor model had all items loading onto one factor. A change in the chi-square test showed the five-factor model produced a significant improvement in chisquares over the alternative models (see Table 1).

We examined convergent validity of each measurement relative to assumed theoretical constructs by analyzing the composite reliability (CR) and the average variance extracted (AVE). The critical values for CR and AVE are 0.7 and .5, respectively (Fornell \& Larcker, 1981). See Table 2. 
Table 2. Measurement Items and Validity Assessment

\begin{tabular}{|c|c|}
\hline 5-FactorModel fit ${ }^{1}:$ CFI $=0.96$, RMSEA $=0.08$, IFI $=0.96$, SRMR $=0.05$ & SFL \\
\hline \multicolumn{2}{|l|}{ Role Ambiguity (RA) } \\
\hline \multicolumn{2}{|l|}{$\mathrm{CR}=0.92, \mathrm{AVE}=0.72, \mathrm{MSV}=0.08$} \\
\hline \multicolumn{2}{|l|}{ Please rate how much you disagree to agree... } \\
\hline RA1: I do not have clearly planned goals and objectives for my job. & .74 \\
\hline RA2: I do not know exactly what is expected of me. & .86 \\
\hline RA3: I do not know what my responsibilities are. & .91 \\
\hline RA4: I do not feel certain about how much responsibility I have. & .86 \\
\hline RA5: My responsibilities are not clearly defined & .87 \\
\hline \multicolumn{2}{|l|}{ Role Conflict (RC) } \\
\hline \multicolumn{2}{|l|}{$\begin{array}{l}\mathrm{BP}: \mathrm{CR}=0.92, \mathrm{AVE}=0.57, \mathrm{MSV}=0.38 \mid \mathrm{AP}: \mathrm{CR}=0.92, \mathrm{AVE}=0.78, \mathrm{MSV}=0.41 \\
\text { Please rate how much you disagree to agree } . .\end{array}$} \\
\hline RC1: I work with two or more groups who operate quite differently. & .53 \\
\hline $\mathrm{RC} 2$ : I often get myself involved in situations in which there are conflicting requirements. & .82 \\
\hline RC3: There are unreasonable pressures for better performance. & .70 \\
\hline RC4: I am often asked to do things that are against my better judgement. & .74 \\
\hline RC5: I receive an assignment without adequate resources and materials to execute it. & .79 \\
\hline RC6: I have to buck a rule or policy in order to carry out a policy. & .80 \\
\hline $\mathrm{RC7}$ : I receive incompatible requires from two or more people. & .81 \\
\hline RC8: I have to do things that should be done differently under different conditions. & .84 \\
\hline \multicolumn{2}{|l|}{ Role Overload (RO) } \\
\hline \multicolumn{2}{|l|}{$\mathrm{CR}=0.91, \mathrm{AVE}=0.78, \mathrm{MSV}=0.38$} \\
\hline \multicolumn{2}{|l|}{ Please rate how much you disagree to agree... } \\
\hline RO1: The amount of work I am expected to do is too great. & .79 \\
\hline RO2: I never seem to have enough time to get everything done at work. & .85 \\
\hline RO3: It often seems like I have too much work for one person to do. & .99 \\
\hline \multicolumn{2}{|l|}{ Bottom-line Mentality (BLM) } \\
\hline \multicolumn{2}{|l|}{$\mathrm{CR}=0.92, \mathrm{AVE}=0.72, \mathrm{MSV}=0.16$} \\
\hline \multicolumn{2}{|l|}{ When working within my organization... } \\
\hline BLM1: I treat the bottom line as more important than anything else & .89 \\
\hline BLM2: I am solely concerned with meeting the bottom line. & .92 \\
\hline BLM3: I care more about profits than employee well-being. & .80 \\
\hline BLM4: I only care about the business. & .80 \\
\hline
\end{tabular}

Note. 5-Factor Model $\mathrm{Fit}^{1}=$ based on using 5-factor model constructs without parceled items (RA, RO, BLM), construct with parceled items (RC), and control variable of social desirability.

$\mathrm{SFL}=$ standardized factor loading; $\mathrm{CR}=$ composite reliability; $\mathrm{AVE}=$ average variance extracted; and $\mathrm{MSV}=$ maximum shared variance with other constructs. RMSEA = root mean squared error of approximation, IFI = incremental fit index, CFI = comparative fit index, SRMR = standardized root mean residual. $\mathrm{BP}=$ before parceling items, $\mathrm{AP}=$ after parceling items. ${ }^{\text {a }}$ Items are measured with seven-point Likert scales.

Correlations, means, standard deviations, and reliabilities for study variables are reported in Table 3.We utilized SPSS to run multiple regression to estimate the dependent variable model and examine the relationship of the study variables. The regression model developed to answer research questions 3 is shown below: 
Table 3. Descriptive Statistics, Correlations, and Scale Reliabilities

\begin{tabular}{llllllll}
\hline & $\mathrm{M}$ & $S D$ & 1 & 2 & 3 & 4 & 5 \\
\hline 1. Role ambiguity & 5.69 & .98 &. $\mathbf{9 2}$ & & & & \\
2. Role conflict & 3.41 & 1.38 & $-23^{* *}$ &. $\mathbf{9 1}$ & & & \\
3. Role overload & 3.73 & 1.68 & $-.15^{*}$ & $.59^{* *}$ &. $\mathbf{9 1}$ & & \\
4. BLM & 3.26 & 1.47 & .08 & $.35^{* *}$ & $.24^{* *}$ & $\mathbf{. 9 2}$ & \\
5. Social desirability & 5.60 & 2.76 & .08 & .05 & -.01 & .00 & $\mathbf{. 7 8}$ \\
\hline
\end{tabular}

Note. $\mathrm{N}=181$. Cronbach's Alphas are in boldface.

$\mathrm{BLM}=$ bottom-line mentality.

p $<.05 .{ }^{* * *}$ p <.01. ${ }^{* * * *} \mathrm{p}<.001$.

$\mathrm{Y}=\mathrm{b}_{0}+\mathrm{b}_{1} \mathrm{x}_{1}+\mathrm{b}_{2} \mathrm{x}_{2}+\mathrm{b}_{3} \mathrm{x}_{3}+\mathrm{b}_{4} \mathrm{x}_{4}$ where:

$\mathrm{Y}=$ mean score of the BLM scale as reported by the survey respondents

$\mathrm{b}_{0}=$ intercept

$\mathrm{x}_{1}=$ summation score of Social Desirability scale reported by the survey respondents

$\mathrm{x}_{2}=$ mean score of the Role Ambiguity scale reported by the survey respondents

$\mathrm{x}_{3}=$ mean score of the Role Conflict scale as reported by the survey respondents

$\mathrm{x}_{4}=$ mean score of the Role Overload scale as reported by the survey respondents

Table 4 reports the regression results, two tailed significance of the three independent variables and control on the dependent variable.

Research questions 1 and 2 are answered in the affirmative as all of the surveys used to measure the research variables were found to be reliable, as the composite reliabilities all ranged between .91 and .94 .

Research question 3 is answered only partially in the affirmative. Role ambiguity and role conflict were found to be statistically significant in their effect on bottom line mentality, however, role overload was not found to significantly impact bottom line mentality, see Table 4.

Table 4. Regression Results for Overall Model

\begin{tabular}{llllll}
\hline Model & B & $S E$ & SCB & t & $\mathrm{R}^{2}$ \\
\hline Dependent variable model: BLM & & & & & .15 \\
Constant & 2.49 & 0.41 & & & \\
Social desirability & -0.02 & 0.04 & -0.03 & -0.43 & \\
Role ambiguity & 0.26 & 0.11 & 0.17 & $2.43^{* *}$ & \\
Role conflict & 0.38 & 0.09 & 0.35 & & \\
Role overload & 0.05 & 0.08 & 0.06 & 0.65 & \\
\hline
\end{tabular}

Note. $\mathrm{N}=181$. Unstandardized regression coefficients are reported.

${ }^{*} \mathrm{p}<.05 .{ }^{* *} \mathrm{p}<.01 .{ }^{* * *} \mathrm{p}<.001$.

\section{Discussion.}

This study expands the COR literature as a potential explanation of workers to adopt or develop BLMs resulting from a loss of resources, represented by work role stressors. Contrary to the literature, role overload did not significantly impact BLM. This finding was somewhat surprising based on role overload was expected to consume cognitive resources. Significant support was found for role ambiguity and role conflict on bottom-line mentality. Possibly, work role stressors function as an ongoing cognitive war between the employee and their job, which depletes the person over time because of using cognitive and emotional resources to deal with frustrations. Arguably, as a result of wanting simplification from role stressors, most likely being vulnerable from the stressors, the employee accepts or adopts a bottom-line mentality. In essence, BLMs are quite possibly born out of stressful work environments. 


\section{Implications for Practice}

This study has several practical lessons. First, the importance of role stressors for an employee should not be underestimated by both parties, management and employee. If the individual has a lack of clarity of information, employment expectations, and/or method to complete job duties, they will experience role ambiguity. As such, the ambiguity role stressor compared to other role stressors may be a catalyst to provoking a BLM, which has been found to be associated with social undermining and deviance.

Secondly, role stressors involving ambiguity and conflict are associated with consuming mental resources that can impact employee output and performance. In other words, when these role stressors are present, it is likely that an employee will have a decreased ability to control their behavior, emotions, and (or) thoughts. The problem of this decreased ability is an employee's work out and performance will be likely to decline. In a study by O'Driscoll and Beehr (1994), it was found that supervisors along with role stressors strongly impact the employee and their work. This study confirmed their finding also providing an explanation of what may be occurring with the employee and their mental resources.

Learning more about how role conflict, role overload, and ambiguity are associated to BLMs can fill a gap in the literature to understand psychological functions that may be occur as coping mechanisms. The more that is understood about this relationship; other outcomes of BLM can be better understood, such as deviant workplace behavior, burnout, or possible compromised ethics

\section{Limitations and Future Directions}

This study has several limitations. A weakness is the data sample consists of workers from nonspecific organizations. This being said, caution should be exercised when generalizing the results. Generalization of the findings this study may vary by organization and/or possibly gender. Exploring this study further relative to these areas could make for a fruitful contribution in understanding the association of stress to BLMs for specific organizations and people. Finally, results of this study are based on self-reported measures. Regardless of these limitations, the authors believe their findings are important for the literature concerning workers and BLMs.

\section{References}

Appelbaum, S. H., \& Shapiro, B. T. (2006). Diagnosis and Remedies for Deviant Workplace Behaviors. Journal of American Academy of Business, Cambridge, 9(2), 14-20.

Bagozzi, R. P., \& Edwards, J. R. (1998). A general approach for representing constructs in organizational research. Organizational research methods, 1(1), 45-87.

Bolino, M. C., \& Turnley, W. H. (2005). The Personal Costs of Citizenship Behavior: The Relationship between Individual Initiative and Role Overload, Job Stress, and Work-Family Conflict. Journal of Applied Psychology, 90(4), 740-748. doi:10.1037/0021-9010.90.4.740

Cohen, S., \& Wills, T. A. (1985). Stress, social support, and the buffering hypothesis. Psychological bulletin, 98(2), 310.

Coverman, S. (1989). Role overload, role conflict, and stress: Addressing consequences of multiple role demands. Social forces, 67(4), 965-982.

Fornell, C., \& Larcker, D. F. (1981). Structural equation models with unobservable variables and measurement error: Algebra and statistics. Journal of marketing research, 382-388.

Greenbaum, R. L., Mawritz, M. B., \& Eissa, G. (2012). Bottom-line mentality as an antecedent of social undermining and the moderating roles of core self-evaluations and conscientiousness. Journal of Applied Psychology, 97(2), 343-359. doi:10.1037/a002521

Halbesleben, J. R., Neveu, J.-P., Paustian-Underdahl, S. C., \& Westman, M. (2014). Getting to the "COR" understanding the role of resources in conservation of resources theory. Journal of Management, 40(5), 1334-1364.

Hall, D. T. (1972). A Model of Coping with Role Conflict: The Role Behavior of College Educated Women. Administrative Science Quarterly, 17(4), 471-486. doi:10.2307/2393827

Hobfoll, S. E. (1989). Conservation of resources: A new attempt at conceptualizing stress. American psychologist, 44(3), 513. 
House, R. J., Schuler, R. S., \& Levanoni, E. (1983). Role conflict and ambiguity scales: Reality or artifacts? Journal of Applied Psychology, 68(2), 334-337. doi:10.1037/0021-9010.68.2.334

Kahn, R. L., \& Byosiere, P. (1992). Stress in organizations.

Karasek Jr, R. A. (1979). Job demands, job decision latitude, and mental strain: Implications for job redesign. Administrative science quarterly, 285-308.

Lazarus, R. S. (1966). Psychological stress and the coping process. New York: McGraw-Hill.

Mitchell, M. S., \& Ambrose, M. L. (2007). Abusive supervision and workplace deviance and the moderating effects of negative reciprocity beliefs. Journal of Applied Psychology, 92(4), 1159.

O'Driscoll, M. P., \& Beehr, T. A. (1994). Supervisor behaviors, role stressors and uncertainty as predictors of personal outcomes for subordinates. Journal of organizational Behavior, 15(2), 141-155.

Peterson, M. F., Smith, P. B., Akande, A., Ayestaran, S., Bochner, S., Callan, V., Viedge, C. (1995). Role Conflict, Ambiguity, and Overload: A 21-Nation Study. The Academy of Management Journal, 38(2), 429-452. doi: $10.2307 / 256687$

Rizzo, J. R., House, R. J., \& Lirtzman, S. I. (1970). Role Conflict and Ambiguity in Complex Organizations. Administrative Science Quarterly, 15(2), 150-163. doi:10.2307/2391486

Sims, R. R. (1992). The challenge of ethical behavior in organizations. Journal of Business Ethics, 11(7), 505513.

Spreitzer, G. M. (1995). Psychological empowerment in the workplace: Dimensions, measurement, and validation. Academy of management Journal, 38(5), 1442-1465.

Strahan, R., \& Gerbasi, K. C. (1972). Short, homogeneous versions of the Marlowe-Crowne Social Desirability Scale. Journal of clinical psychology.

Weick, K. E. (1995). Sensemaking in Organizations. In. Thousand Oaks, CA: Sage Publications.

Weick, K. E., Sutcliffe, K. M., \& Obstfeld, D. (2005). Organizing and the Process of Sensemaking. Organization Science, 16(4), 409-421. doi:10.2307/25145979

Welbourne, T. M., Johnson, D. E., \& Erez, A. (1998). The role-based performance scale: Validity analysis of a theory-based measure. Academy of management journal, 41(5), 540-555.

Wolfe, D. M. (1988). Is There Integrity in the Bottom Line: Managing Obstacles to Executive Integrity. In S. Srivastva (Ed.), Executive integrity: The search for high human values in organizational life. San Francisco, CA: US: Jossey-Bass, xxii. 